\title{
Reflections on the recent world events
}

\author{
Louis-Philippe Boulet MD FRCPC FCCP, President, Canadian Thoracic Society
}

$I^{2}$ would never have imagined that I would write my last editorial before passing the presidency of the Canadian Thoracic Society (CTS) to Dr Irvin Mayers after such outrageous events as those of September 11, 2001. It is difficult not to speak about this new world environment, particularly in light of the recent threat of bioterrorism. Life will probably never be the same; an additional element of uncertainty will now exist for all people, forcing us to look at things in a different way. After the tragic events of September 11, the CTS offered its sincere sympathies and help to our American colleagues. On that tragic day, we shared the frustration of our colleagues in health care who were waiting for the victims of the attack but soon realized that most victims were dead and nothing could be done to help save more lives.

This is also a difficult period for the various medical societies. The American Thoracic Society has its office in Manhattan, New York; one can only imagine the anxiety, fear and sadness that their staff have experienced. The annual meeting of the American College of Chest Physicians and that of the CTS was held in Philadelphia, Pennsylvania in a context that was, unfortunately, less favourable than past meetings.

The implications of such events are profound, not only in our minds and memories, but in our daily life activities. Some participants of international and national meetings have been reluctant to travel to major scientific events. Economic changes and the threat of spreading infections from bioterrorist attacks have contributed to an increased 'anxiety level' in the population. We should not overreact to these events or let this climate freeze all initiatives, but rather, we should shift some resources and activities toward the prevention, education and treatment of these new problems. Of course, we need to be prepared to deal with the health hazards of possible terrorist attacks in their various forms. On the other hand, the burden of war will affect the refugees and those involved in those conflicts. Diseases such as tuberculosis and other respiratory infections will like-

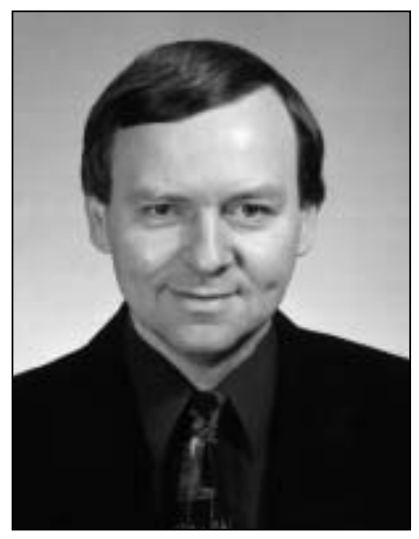
ly flourish during these conflicts. Although these problems should be addressed, they should not distract us from current major threats to the world population; infectious diseases, malnutrition and poor health affect many countries. At home, our people are, unfortunately, still suffering and dying from diseases that are either preventable or for which research should bring new hope.

Extremism is a social plague and will certainly not be eradicated tomorrow. We have to learn more about the causes of these behaviours and be better prepared to face the difficulties associated with new threats. We should not withdraw from our responsibilities and current activities, but be proactive in trying to improve the situation and support initiatives that could respond to current problems. Although it is not the only means to improve a complex situation, the gap between wealthy and poor populations should be reduced. Major differences exist between health care systems, particularly in underdeveloped countries. As an exam- 
ple, current treatment guidelines may often not be applied in some parts of the world because people do not have access to, or cannot afford, these treatments. The differences between poor and rich countries, as well as feelings of injustice, may foster unfortunate actions that are so destructive - not only for those affected, but also for those performing these acts. Positive actions need to emerge from these difficult times. We need to increase our sense of planetary responsibility, and our involvement in projects that promote peace and health for all humankind on a long term basis. 


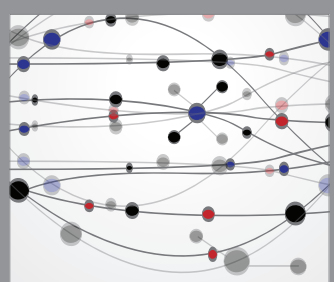

The Scientific World Journal
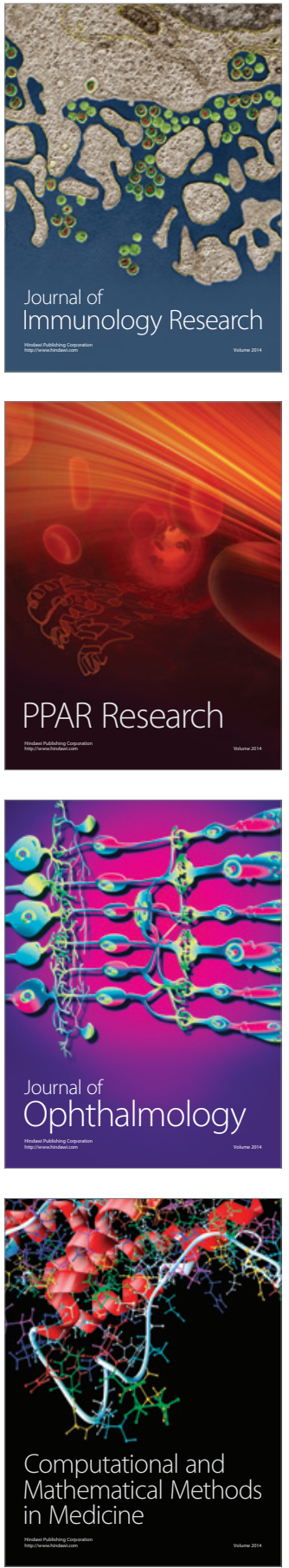

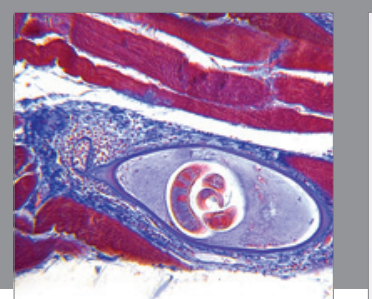

Gastroenterology Research and Practice

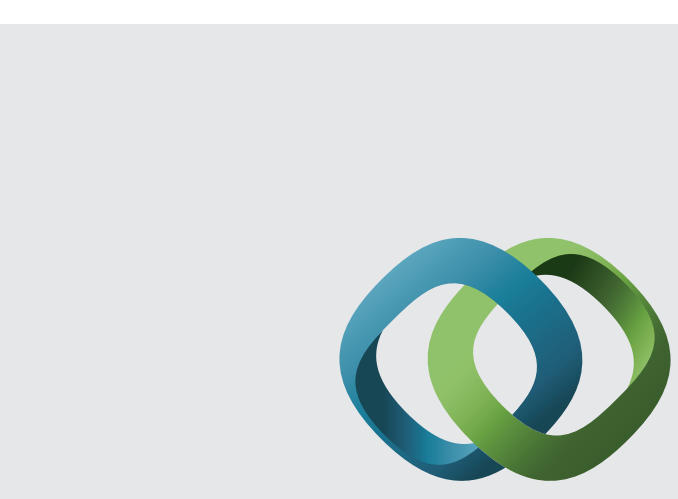

\section{Hindawi}

Submit your manuscripts at

http://www.hindawi.com
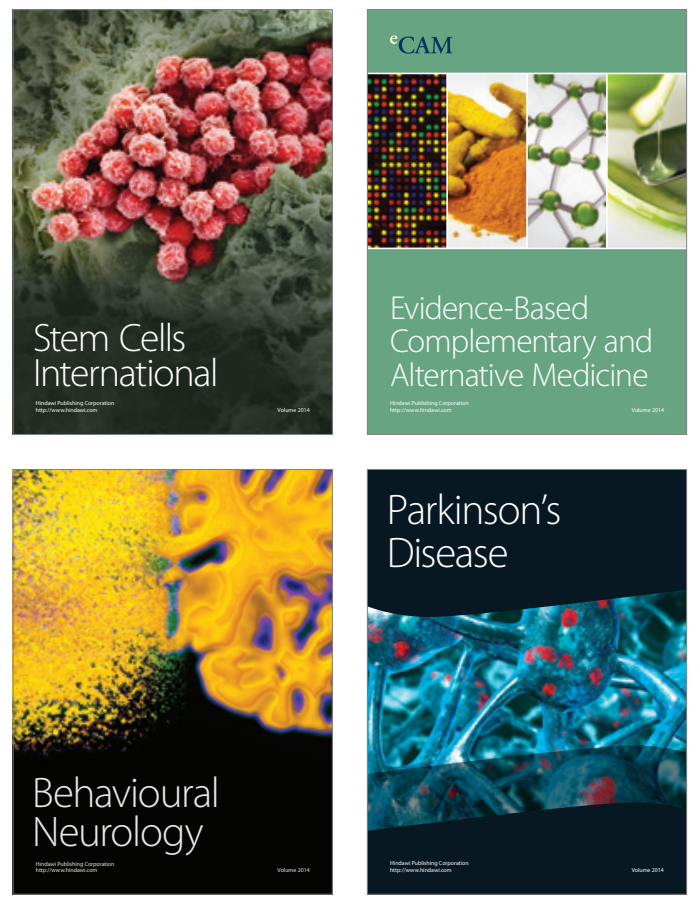
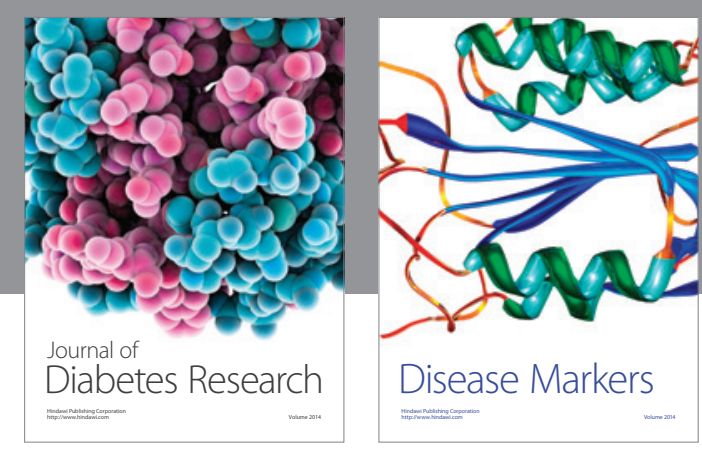

Disease Markers
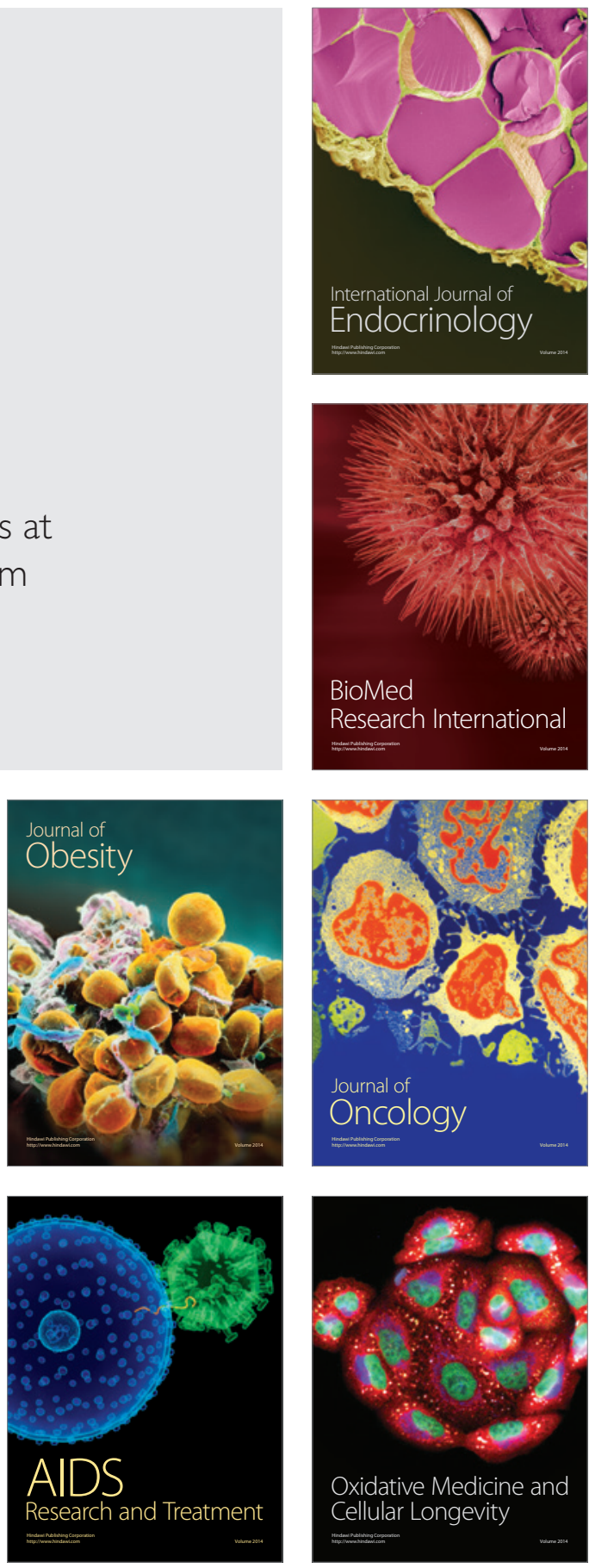